\title{
ANALISA PENINGKATAN KUALITAS PRODUK KERTAS DENGAN PENDEKATAN METODE SIX SIGMA PADA PT. SPM
}

\author{
Moh. Fahrizal Akbarudin Kurniawan \\ e-mail : frizal75@gmail.com \\ Teknik Industri, Fakultas Teknik \\ Universitas Marif Hasyim Latif, Sidoarjo, Indonesia
}

\begin{abstract}
ABSTRAK
Pada saat ini kebutuhan akan produk kertas pada konsumen terus meningkat, terutama pada kebutuhan kertas minyak. Seiring dengan berkembangnya sektor dagang terutama pada perdagang makanan di indonesia. Oleh sebab itu kertas minyak adalah suatu produk yang begitu vital bagi para pedagang makanan di indonesia. Metode penelitian yang digunakan saat melakukan penelitian ini yaitu dengan metode yang menamkan Six sigma dengan tahapan DMAIC (Define, Measure, Analyze, Improve, Control). Dari hasil analisis penelitian yang dilakukan kapabilitas sigma pada proses produksi kertas minyak pada tahun 2018 yaitu dengan nilai 3,83\% dan DPMO sebesar 9870,556 per satu juta peluang. Berdasarkan penelitan bahwa pengendalian kulaitas di perusahaan sudah cukup berjalan akan tetapi kurang maksinal, maka dari itu perlu adanya perbaikan pada sektor: manusia (karyawan), mesin, bahan baku, metode dan lingkungan, guna menghasilkan produk kertas minyak yang berkualitas.
\end{abstract}

Kata kunci: DMAIC, Diagram Pareto, Pengendalian Kualitas, SIX SIGMA

\section{PENDAHULUAN}

Persaingan industri kertas antara satu perusahaan dengan perusahaan lain sangatlah ketat, masing-masing perusahaan ingin yang terbaik dan maju untuk memperoleh keuntungan yang besar. Dibutuhkan pengendalian serta perhitungan yang tepat pada masalah produksi supaya perusahaan bisa bertahan di persaingan pasar pada era saat ini, (Purnama, Suparto, \& Dinata, 2016). Pada PT. SPM saat ini jumlah produk cacat dalam produksi hampir mencapai angka 3,95\% dari target maksimal 3,40\%, jika problem tersebut bila tidak segera cepat di tindak lanjuti akan berdampak kurang baik bagi perusahaan (Ireland \& Dale, 2001). Adapun 5 macam masalah dari cacat produk dalam produksi kertas LWK (kertas bungkus) pada PT.SPM,Tbk yaitu : kembung (plastik mengelupas, PE kurang, lipat pada kertas, lubang pada kertas,bocor bila terkena air).

Sehingga dari macam gagalnya produk itu dapat menghambat proses pengiriman produk pada cutomer, banyaknya pesanan dari luar tidak sebanding dengan produk yang di hasilkan, hal semacam itu akan berakibat kurang baik bagi perusahaan, larinya customer itu adalah hal terburuk pada perusahaan. Pada penelitian ini digunakan alat Six Sigma karena metode ini sangat cocok guna untuk melakukan penekanan terhadap jumlah reject yang dilakukan pada saat proses produksi berlangsung sehingga dapat tercapainya produk yang baik juga tidak banyak menimbulkan barang cacat produk, (Antony, Kumar, \& Labib, 2008).

\section{METODE PENELITIAN}

Pada peneletian kali ini digunakan alat six sigma dikarenakan adalah metode yang terbaik dalam penelitian ini, (Barnabè, Giorgino, Guercini, \& Bianciardi, 2016). Dalam penerapan metode six sigma ini ada beberapa langkah-langkah yang harus diperhatikan dalam implementasi ini, adapun langkahlangkahnya sebagai berikut.

\section{Define}

Saat tahapan ini yang perlu dilakukan yaitu mendefinisikan seluruh penyebab sumber defect yang paling signifikan dalam produk, yang menyebabkan terjadinya kecacatan produksi. Adapun macam-macam cacat dalam produk adalah sebagai berikut, yaitu: kembung (lapisan plastik tidak melekat pada permukaan kertas), bocor, lipat, dan plastik kurang. Dengan mendefinisikan standar kaualitas dalam produk serta mendefinisikan rencana dalam perbaikan, (Gaspersz, 2002).

\section{Measure}

Selanjutya adalah tahapan pengukuran dengan cara analisa diagram kontrol (p-chart). Diagram kontrol P berfungsi sebagai atribut pada sifat-sifat pada barang berdasarkan proporsi pada jumlah kejadian apabila itu diterima atau ditolak, 
langkah-langkah dalam menyusun diagram ini sebagai berikut:

a) Mengambil populasi dan sampel

Populasi yang diambil pada analisa ini adalah jumlah produk yang dihasil-kan pada kegiatan produksi kertas minyak.

b) Memeriksa karakteristik dengan cara menghitung nilai mean

$$
p-\frac{\sum n p}{\sum_{n}}
$$

dimana :

$\mathrm{n}$ : jumlah sampel

np : jumlah kecacatan

p : rata-rata proporsi kecacatan

c) Menentukan batas kendali pada pengawasan untuk mendapatkan nilai UCL (Upper Control Limit / batas kontrol atas) dan LCL (Lower Control Limit / batas kontrol bawah).

$$
\begin{aligned}
& v C L=p+\sqrt[3]{\frac{p(1-p)}{n}} \\
& \text { ICL }=p-\sqrt[3]{\frac{p(1-p)}{n}}
\end{aligned}
$$

dimana

$$
\begin{aligned}
& \text { UCL : Upper Control Limit } \\
& \text { LCL : Lower Control Limit } \\
& \text { p : rata-rata proporsi kecacatan } \\
& \text { n : jumlah sampel }
\end{aligned}
$$

\section{Analyze}

Tahapan Analyze adalah Menganalisa dengan menggunakan 2 diagram yaitu:

a. Digram pareto, dengan mengurutkan berdasarkan tingkat proporsi kecacatan paling besar sampai dengan paling kecil. Diagram ini dapat membantu untuk memfokus-kan pada masalah kecacatan produk yang lebih sering terjadi, yang mengisyaratkan masalah-masalah mana yang bila ditangani dapat menghasilkan manfaat yang besar.

b. Diagram sebab - akibat, berfungsi sebagai pedoman pada proses produksi sehingga dapat memaksimalkan nilai-nilai kesuksesan pada kualitas produk diperusahaan pada waktu yang bersamaan, agar dapat mengoptimalkan segala kegagalan.

\section{Improve}

Adalah tahapan peningkatan dan perbaikan kualitas dengan melakukan pengukuran dari kerusakan, peluang, dan proses kapabilitas, rekomendasi untuk perbaikan, menganalisa, dan tindakan perbaikan.

\section{Control}

Adalah tahapan akhir dari peningkatan dan perbaikan kualitas dengan memastikan standar kinerja secara efektif sehingga nilai-nilai peningkatannya dapat terjaga yang kemudian didokumentasikan serta disebarluaskan yang berfungsi sebagai langkah-langkah untuk perbaikan pada proses berikutnya, (Aziza \& Afandi, 2018)

\section{HASIL DAN PEMBAHASAN}

Data-data yang dikumpulkan tersebut terdiri dari data produksi serta cacat yang dihasilkan dalam proses produksi kertas minyak selama 1 (satu) tahun.

Tabel 1. Data Produksi Dari Perusahaan

\begin{tabular}{|l|c|c|c|}
\hline \multicolumn{1}{|c|}{ Bulan } & $\begin{array}{c}\text { Jumlah } \\
\text { Produksi } \\
\text { (Ton) }\end{array}$ & $\begin{array}{c}\text { Jumlah } \\
\text { Produk } \\
\text { Cacat } \\
\text { (Ton) }\end{array}$ & $\begin{array}{c}\text { Prosentase Produk } \\
\text { Cacat (\%) }\end{array}$ \\
\hline Januari & 1.289 & 45,11 & 3,50 \\
\hline Februari & 1.174 & 40,85 & 3,48 \\
\hline Maret & 1.292 & 46,77 & 3,62 \\
\hline April & 1.198 & 50,44 & 4,21 \\
\hline Mei & 1.302 & 51,04 & 3,92 \\
\hline Juni & 1.082 & 51,07 & 4,72 \\
\hline Juli & 1.321 & 43,59 & 3,30 \\
\hline Agustus & 1.217 & 56,10 & 4,61 \\
\hline September & 1.273 & 50,54 & 3,97 \\
\hline Oktober & 1.310 & 53,32 & 4,07 \\
\hline November & 1.267 & 60,94 & 4,81 \\
\hline Desember & 1.298 & 41,15 & 3,17 \\
\hline Total & 15.023 & 590,92 & 49,24 \\
\hline Rata-rata & 1.252 & & \\
\hline
\end{tabular}

Tahap Pendefinisian (Define)

Beberapa hal yang harus dilakukan dalam tahap ini yang terkait dengan perbaikan produk dalam six sigma yaitu dengan menetapkan standar maupun spesefikasi kualitas produk kertas minyak, sesuai dengan harapan konsumen. Meskipun dalam implementasinya masih saja ditemukan adanya kecacatan atas standar kualitas yang sudah ditetapkan di proses produksi. Kemudian dilakukan pengidentifikasian karakteristik CTQ pembentuk dari produk yang diteliti, serta mendefinisikan peta alur produksi dan cacat produk yang di tetapkan oleh perusahaan (Gaspersz, 2003). Adapun jenis cacat produk pada perusahaan yaitu:

1. Cacat karena kembung (plastik tidak lengket)

2. Cacat karena plastik kurang : terjadinya caca tini di karenakan adanya kurang sesuainya ukuran plastik dengan ukuran ketas

3. Cacat karena kertas lipat : terjadinya cacat ini biasanya hal ini di ttandai dengan lembebnya permukaan kertas. 
4. Cacat karena kertas bocor : saat uji kelayakan dengan menyiramkan air panas kepermukaan kertas maka akan terjadi kebocoran pada kertas tersebut.

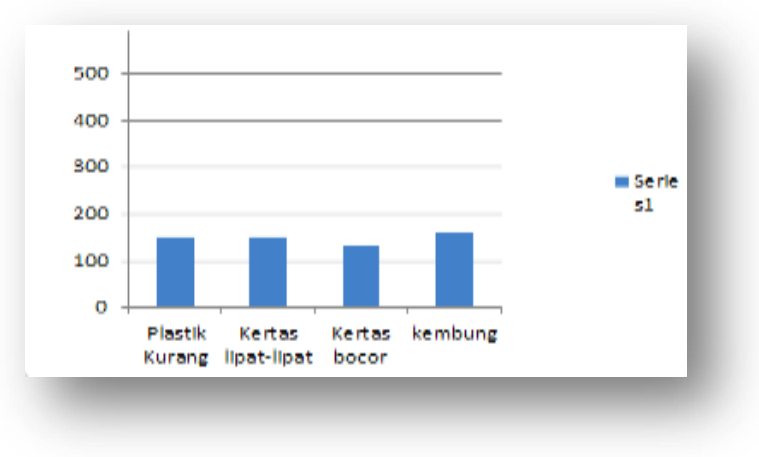

Gambar 1. Histogram cacat produk

\section{Tahap Mengukur (Measure)}

Dalam tahap pengukuran (measure),terdiri dari dua tahapan yaitu: Analisa Diagram Kontrol (P-Chart), Analisa ini dilakukan dengan menggunakan diagram kontrol jenis P-Chart. Data yang dipakai yaitu data jumlah produksi kertas minyak (LWK) pada PT. SPM, Tbk, selama periode di tahun 2018 pada bulan Januari sampai bulan Desember 2018 yaitu dengan total produksi 15.153 ton, sementara jumlah cacat yang ditemukan dari empat penyebab kecacatan produk kertas minyak sebanyak 590,92 ton. Mean (CL) atau rata-rata produk akhir bisa dihitung dengan cara sebagai berikut.

Berdasarkan peta kendali P dapat dihitung sebagai berikut:

a. Hasil perhitungan persentase kerusakan

$$
\begin{aligned}
\bar{P}=C L & =\frac{\sum n p}{\sum n} \\
& =\frac{590,92}{15023}=0,039
\end{aligned}
$$

b. Langkah-langkah selanjutnya yaitu menghitung nilai proporsi produk cacat (P) perbulan. Yaitu banyaknya produk cacat (np) perbulan dibagi dengan jumlah produksi perbulan (n). Maka diperoleh hasil proporsi produk cacat pada bulan pertama januari 2018 ( periode ke-1), dengan $n=1.289$ ton dan $n p=45,11$ ton adalah:

$$
\begin{aligned}
P=\frac{n p}{n} & =\frac{45,11}{1.289} \\
& =0,035=3,5 \%
\end{aligned}
$$

c. Hasil Perhitungan Upper Control Limit (UCL)Mencari jumlah batas kendali atas (UCL) dari batas kendali bawah (LCL) batas kendali di hitung secara perperiode karena jumlah produk yang dihasilkan tidak konsisten. Pada periode pertama bulan januari $(n=1289)$

$$
\begin{aligned}
U C L & =\bar{P}+3 \sqrt{\frac{P(1=\bar{P})}{n}} \\
& =0,039+3 \sqrt{\frac{0,039(1-0,039)}{1289}} \\
=0,0556 &
\end{aligned}
$$

d. hasil perhitungan Lower Control Limit (LCL)

$$
\begin{aligned}
L C L & =\bar{P}-3 \sqrt{\frac{\bar{P}(1-\bar{P})}{n}} \\
& =0,039-3 \sqrt{\frac{0,039(1-0,039)}{1289}} \\
& =0,0231
\end{aligned}
$$

Pada tabel dibawah ini merupakan hasil perhitungan UCL (Upper Control Limit) dan LCL (Lower Control Limit) mulai bulan januari mencapai bulan desember 2018.

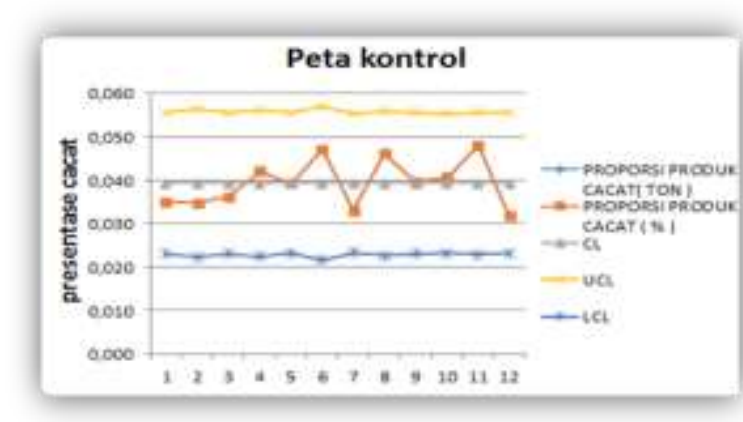

Gambar 2. Peta Kontrol

Dari hasil perhitungan dapat diketahui bahwa proses produksi kertas minyak masih rendah. Tampak pada DPMO yang masih tinggi, yaitu 3,83\% yang dapat diartikan bahwa dalam satu juta kesempatan yang ada, masih terdapat 9870,556 ton kemungkinan bahwa proses produksi itu menghasilkan produk cacat. Nilai sigma pada produksi kertas minyak masih dibawah rata-rata. Maka pengendalian kualitas harus lebih ditingkatkan, agar menunjukkan pola DPMO kecacatan produk level sigma yang rendah akan mampu meningatkan produktivitas bagi perusahaan. 


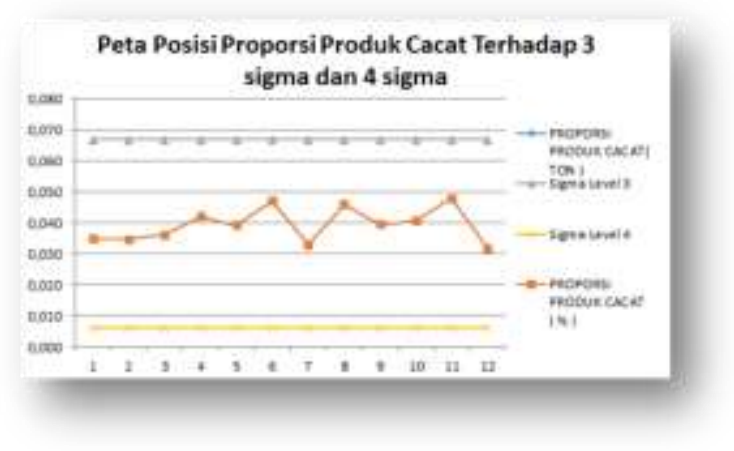

Gambar 3. Peta Posisi Produk Cacat dari level 3 sigma Dan 4 Sigma

\section{Tahap Analisa (Analyze)}

Tahap ini yaitu pembuatan diagram pareto serta diagram sebab akibat, untuk mengetahui penyebab doinan cacat produk dan usulan perbaikan.

\section{Diagram pareto}

Diagram pareto berguna untuk mengetahui jenis cacat yang sering terjadi, yang meandakan masalah-masalah mana yang apabila ditangani mendapatkan manfaat yang besar. Data yang diolah untuk megetahui presentase produk cacat. Dari tabel perhitungan persentase komulatif di atas terdapat empat jenis produk cacat, yang presentasenya di dapat dari total berat jenis cacat tersebut dibagi dengan total berat cacat keseluruhan di kali 100\%.

Tabel 2. Hasil Perhitungan Persentase Cacat Dan Presentase Komulatif Kertas Minyak.

\begin{tabular}{|c|l|c|c|c|}
\hline No & \multicolumn{1}{|c|}{ Jenis Cacat } & $\begin{array}{l}\text { Jumlah } \\
\text { Cacat } \\
\text { (Ton) }\end{array}$ & $\begin{array}{c}\text { Presentase } \\
(\%)\end{array}$ & $\begin{array}{c}\text { Presetase } \\
\text { komulatif }\end{array}$ \\
\hline 1 & $\begin{array}{l}\text { Plastik } \\
\text { Mengelupas } \\
\text { (Blowing) }\end{array}$ & 159,35 & $26,99 \%$ & $26,99 \%$ \\
\hline 2 & $\begin{array}{l}\text { Plastik Kurang (PE } \\
\text { kurang) }\end{array}$ & 149,59 & $25,31 \%$ & $52,30 \%$ \\
\hline 3 & $\begin{array}{l}\text { Kertas lipat-lipat } \\
\text { (Fold) }\end{array}$ & 149,54 & $25,30 \%$ & $77,60 \%$ \\
\hline 4 & Bocor (Leakage) & 132,40 & $22,40 \%$ & $100,00 \%$ \\
\hline \multicolumn{2}{|c|}{ Total } & 590,92 & $100,00 \%$ & \multicolumn{2}{|c}{} \\
\cline { 1 - 4 }
\end{tabular}

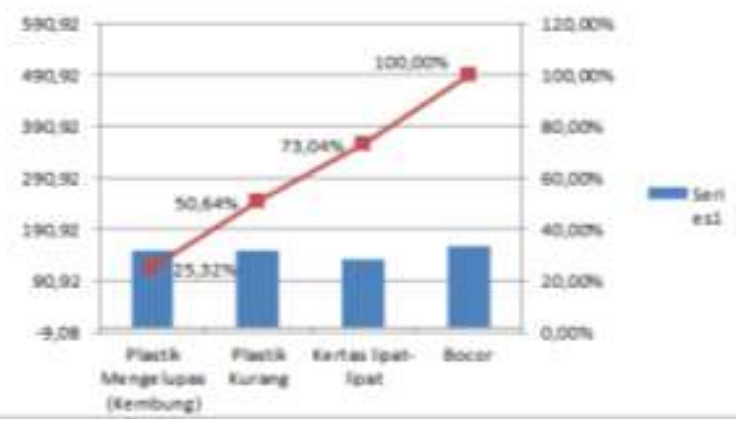

Gambar 4. Diagram Pareto Jenis Cacat Produk Kertas Minyak
Gambar 4, menunjukan diagram pareto cacat yang terjadi pada kertas minyak. Cacat dominan yaitu dengan melihat pada cacat yang memberikan kontribusi lebih dari $80 \%$ untuk semua cacat. Cacat domian dijadikan sebagai penanganan perbaikan pada produk kertas minyak. Adapun cacat dominan yaitu, plastik mengelupas (kembung) (26,96\%), plastik kurang $(25,31 \%)$, lipat-lipat $(25,30 \%)$ bocor $(22,40 \%)$.

\section{Diagram Sebab Akibat (Fish Bone)}

Analisa selanjutnya dilakukan untuk menncari faktor penyebab produk cacat pada produk kertas minyak dalam bentuk diagram sebab akibat. Diagram sebab akibat ini diperoleh dengan cara pengamatan langsung dilapangan dan wawancara kepada pihak yang berkaitan

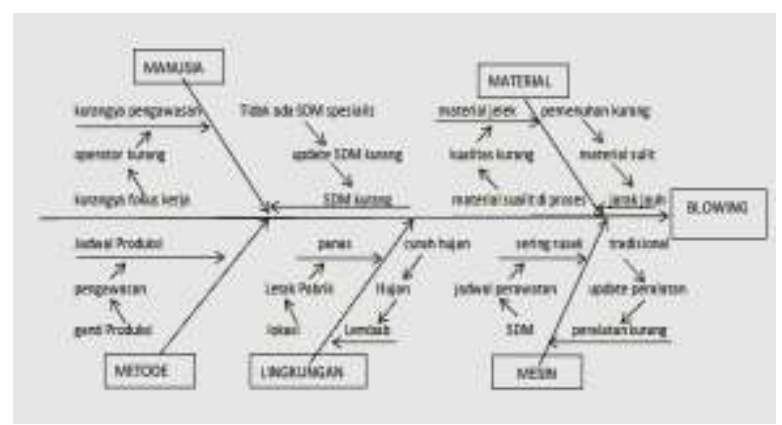

Gambar 5. fish Bone Cacat Kembung (Blowing)

Berdasarkan diagram fishbone Cacat Kembung (Blowing) diatas dapat dilihat bahwa terdapat 5 penyebab yang dapat membuat kecacatan produk pada kertas minyak, adapun 5 penyebab tersebut adalah:

1. Faktor Manusia

a) Kurangnya Fokus dalam bekerja, pengawasan terhadap produk yang dihasilkan juga kurang.

b) Tenaga kerja yang belum handal juga mempengaruhi kualitas produk yang dihasilkan.

2. Faktor Mesin

a) Sering rusaknya pada part mesin, hal itu disebabkan oleh penjadwalan perawatan yang tidak continyu.

b) Peralatan kurang memadai, hal itu disebabkan oleh kurang updatenya peralatan yang digunakan.

3. Faktor Material

a) Material sulit diproses, hal itu disebabkan oleh pemenuhan kualitas material kurang.

b) Material sulit didapat, hal itu dipengaruhi oleh material sulit didapat dan jarak antara gudang material dan proses produksi jauh. 
4. Faktor metode

a) Jadwal produksi tidak teratur, hal itu dipengaruhi oleh kurangnya pengawasan pada penjadwalan.

5. Faktor lingkungan kerja

a) Cuaca lembab, cuaca lembab disebabkan oleh cuaca yang tidak menentu ataupun curah hujan yang begitu tinggi.

Cuaca panas, cuaca panas disebabkan oleh dekatnya pabrik dengan perkotaa

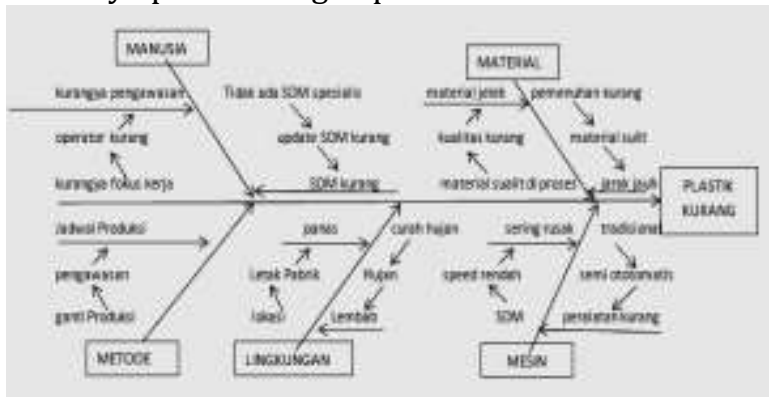

Gambar 6. fish Bone Cacat Plastik kurang

Berdasarkan diagram fishbone plastik kurang diatas dapat dilihat bahwa terdapat 5 penyebab yang dapat membuat kecacatan produk pada kertas minyak yaitu plastik yang kurang, adapun 5 penyebab tersebut adalah:

\section{Faktor Manusia}

a) Kurangnya Fokus dalam bekerja, pengawasan terhadap produk yang dihasilkan.

b) Tenaga kerja yang belum handal juga mempengaruhi kualitas produk yang dihasilkan.

2. Faktor Mesin

a) Spedd mesin terlalu rendah akan berakibat terjadinya kemunculan plastik yang kurang.

b) Peralatan kurang canggih, mesin masih bersifat semi otomatis.

3. Faktor Material

a) Material sulit diproses, hal itu disebabkan oleh pemenuhan kualitas material kurang.

b) Material sulit didapat, hal itu dipengaruhi oleh material sulit didapat dan jarak antara gudang material dan proses produksi jauh.

4. Faktor metode

a) Jadwal produksi tidak teratur, hal ini dipengaruhi oleh kurangnya pengawasan pada penjadwalan.

5. Faktor lingkungan kerja

a) Cuaca lembab, cuaca lembab disebabkan oleh cuaca yang tidak menentu ataupun curah hujan yang begitu tinggi juga kadang tidak menentu.

b) Cuaca panas, cuaca panas disebabkan oleh dekatnya pabrik dengan perkotaan.

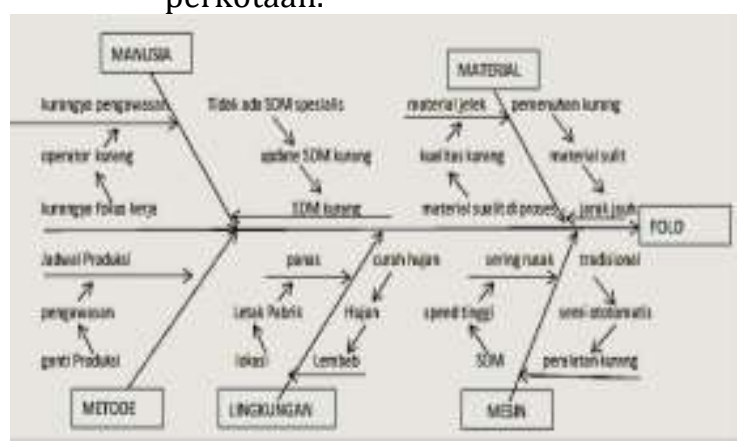

Gambar 7. fish Bone Cacat Lipat (fold)

Berdasarkan diagram fishbone diatas dapat dilihat bahwa terdapat 5 penyebab yang dapat membuat kecacatan produk pada kertas minyak yaitu lipatlipat pada kertas, adapun 5 penyebab tersebut adalah:

1. Faktor Manusia

a) Kurangnya Fokus dalam bekerja, pengawasan terhadap produk yang dihasilkan.

b) Tenaga kerja yang kurang spesialis juga mempengaruhi produk yang dihasilkan.

2. Faktor Mesin

a) Rusaknya part pada mesin dipengaruhi oleh bebrapa faktor yaitu: SDM kurang baik.

b) Peralatan kurang canggih, mesin masih bersifat semi otomatis.

3. Faktor Material

a) Material sulit diproses, hal itu disebabkan oleh pemenuhan kualitas material kurang.

b) Material sulit didapat, hal ini dipengaruhi oleh material sulit didapat dan jarak antara gudang material dan proses produksi jauh.

4. Faktor metode

a) Jadwal produksi tidak teratur, hal itu dipengaruhi oleh kurangnya pengawasan pada penjadwalan.

5. Faktor lingkungan kerja

a) Cuaca lembab, cuaca lembab disebabkan oleh cuaca yang tidak menentu ataupun curah hujan yang begitu tinggi juga kadang tidak menentu.

b) Cuaca panas, cuaca panas disebabkan oleh dekatnya pabrik dengan perkotaan. 
Tahap Perbaikan (Improve)

1.Kembung (Blowing) selanjutnya dilakukan rencana tidakan perbaikan untuk peningkatan kualitas. Setelah diketahui penyebab kecacatan pada produk kertas minyak, maka disusun suatu rekomendasi perbaikan secara umum, utuk menekan tingkat kecacatan produk kertas minyak.

1. Mesin

a) Pergantian part mesin harus yang bersifat modern.

2. Manusia

a) Operator harus memiliki rasa memiliki terhadap pekerjaan atau perusahaan.

b) Diberikan apresiasi kepada karyawan yang berprestasi.

3. Lingkungan

a) Faktor cuaca tidak menentu dapat dilakukan usulan perbaikan dengan Perlu deberikan tempat atau gudang yang baik.

4. Material

a) Perlu pemilihan dan pembelian material dengan kualitas yang baik.

b) Penempatan bahan baku di tempatkan jaraknya paling dekat dengan gudang produksi.

5. Metode

a) Jadwal produksi yang tidak teratur, dapat dilakukan perbaikan dengan Pembuatan jadwal produksi harus lebih teratur.

2.Dalam tahap usulan perbaikan pada cacat plastik kurang ada beberapa usulan perbaikan dari 5 faktor tersebut.

1. Mesin

a) Faktor penyebab dari SDM kurang baik, adapun usulan perbaikanya yaitu dengan Pemberian motivasi yang baik.

b) Faktor penyebab dari Spedd mesin terlalu rendah akan berakibat terjadinya kemunculan plastik yang kurang, adapun usulan perbaikanya yaitu dengan melakukan pengoperasian mesin sesuai SOP yang ditetapkan.

2. Manusia

a) Faktor penyebab dari kurangnya fokus dalam bekerja yaitu operator harus lebih fokus lagi dalam bekerja agar dalam pekerjaanya menghasilkan sesuatu yang baik.

b) Faktor penyebab dari sumber daya manusia kurang memadai, adapun usulan perbaikanya yaitu dengan sumber daya manusia harus tepat sesuai SOP yang telah diterapkan pada perusahaan.

3. Lingkungan

a) Faktor penyebab dari cuaca lembab, adapun usulan perbaikanya yaitu dengan Perlu di berikan tempat yang kering.

b) Faktor penyebab dari cuaca panas, adapun usulan perbaikanya yaitu dengan perlu pemasangan blower guna mengurangi suhu panas pada ruangan.

4. Material

a) Faktor penyebab dari material sulit di proses, adapun usulan perbaikanya dengan perlu pemilihan dan pembelian materian dengan kualitas yang baik.

b) Faktor penyebab dari pemenuhan material kurang, adapun usulan perbaikanya yaitu dengan penempatan material harus berdekatan dengan proses produksi.

5. Metode

a) Faktor penyebab dari Jadwal prosuksi yang tidak teratur, adapun usulan perbaikanya yaitu dengan pemilihan metode yang efektif bagi perusahaan.

3.Dalam tahap usulan perbaikan pada cacat lipatlipat ada beberapa usulan perbaikan dari 5 faktor tersebut.

1. Mesin

a) Faktor penyebab dari Peralatan kurang canggih, mesin masih bersifat semi otomatis , adapun usulan perbaikanya dengan pergantian peralatan yang lebih canggih dan terbaru.

b) Faktor penyebab dari Spedd mesin terlalu tinggi juga akan berakibat terjadinya kemunculan cacat produk, adapun usulan perbaikanya melakukan pengoperasian mesin sesuai SOP yang ditetapkan.

2. Manusia

a) Faktor penyebab dari kurangnya fokus dalam bekerja adalah operator harus lebih fokus lagi dalam bekerja agar dalam pekerjaanya menghasilkan sesuatu yang baik.

b) Faktor penyebab dari sumber daya manusia kurang memadai, adapun usulan perbaikanya yaitu sumber daya manusia harus tepat sesuai SOP yang telah diterapkan pada perusahaan.

3. Lingkungan

a) Faktor penyebab dari cuaca lembab, adapun usulan perbaikanya adalah Perlu di berikan tempat yang kering. 
b) Faktor penyebab dari cuaca panas, adapun usulan perbaikanya adalah Perlu pemasangan blower guna mengurangi suhu panas pada ruangan.

4. Material

a) Faktor penyebab dari material sulit di proses, adapun usulan perbaikanya yaitu denganperlu pemilihan dan pembelian materian dengan kualitas yang baik.

b) Faktor penyebab dari pemenuhan material kurang, adapun usulan perbaikanya yaitu sebagai berikut dengan menempatkan material harus berdekatan dengan proses produksi.

5. Metode

a) Faktor penyebab dari Jadwal prosuksi yang tidak teratur, adapun usulan perbaikanya yaitu dengan pemilihan metode yang efektif bagi perusahaan.

\section{Tahap Evaluasi (Control)}

Tahapan evaluasi yaitu dilakukan untuk mengatasi jumlah cacat yang tidak melebihi 3,95\%. Pengendalian dilakukan antara lain yaitu:

1. Perawatan mesin.

2. Kalibrasi ukur atau alat timbangan.

3. Motivasi karyawan.

4. Bahan baku yang berkualitas.

5. Pembuatan dan pengawasan terhadap SOP.

\section{PENUTUP}

Produk kertas minyak saat ini banyak mengalami cacat sebesar 3,95\%. Dengan menggunakan metode six sigma dibagian produksi kertas minyak dengan nilai sigma berada pada tingkat 3,83\% dengan DPMO 9870,556. Macammacam cacat pada produk kertas minyak antara lain adalah: cacat kembung (Plastik mengelupas) sebanyak 26,99\%, cacat karena plastik kurang sebanyak 25,31\%, cacat karena lipat-lipat pada kertas sebanyak 25,30\%, cacat karena bocor sebanyak 22,40\%. Adapun Faktor-faktor yang mempengaruhi cacat produk pada kertas minyak antara lain adalah: Faktor bahan baku, faktor manusia, faktor mesin faktor metode, faktor lingkungan (Cima et al., 2011).

\section{DAFTAR PUSTAKA}

Antony, J., Kumar, M., \& Labib, A. (2008). Gearing Six Sigma into UK manufacturing SMEs: results from a pilot study. Journal of the Operational Research Society, 59(4), 482-493.

Aziza, N., \& Afandi, M. (2018). ANALISIS DEFECT DAN KUALITAS PRODUK WRITING AND PRINTING PAPER DENGAN SIX SIGMA. Teknika: Engineering and Sains Journal, 2(1), 73-78.

Barnabè, F., Giorgino, M. C., Guercini, J., \& Bianciardi, C. (2016). Performance enhancement and continuous improvement in healthcare: how lean six sigma "hits the target." International Journal of Business and Social Science, 7(5), 21-35.

Cima, R. R., Brown, M. J., Hebl, J. R., Moore, R., Rogers, J. C., Kollengode, A., ... Deschamps, C. (2011). Use of lean and six sigma methodology to improve operating room efficiency in a high-volume tertiary-care academic medical center. Journal of the American College of Surgeons, 213(1), 83-92.

Gaspersz, V. (2002). Metode Kualitas Untuk Pedoman Peningkatan Kualitas. PT. Gramedia Pustaka Utama. Jakarta.

Gaspersz, V. (2003). Metode Analisis Untuk Peningkatan Kualitas. Jakarta: PT Gramedia Pustaka Utama.

Ireland, F., \& Dale, B. G. (2001). A study of total productive maintenance implementation. Journal of Quality in Maintenance Engineering, 7(3), 183-192.

Purnama, J., Suparto, S., \& Dinata, P. C. (2016). PENINGKATAN PRODUKTIVITAS DENGAN IMPLEMENTASI METODE SIX SIGMA PADA PRODUK ELEMENT BOILER. Jurnal Simantec, $5(3)$. 